
2 Research Square
Preprints are preliminary reports that have not undergone peer review.
They should not be considered conclusive, used to inform clinical practice,
or referenced by the media as validated information.

\title{
Study on Changes of 19 Steroids in Plasma From 9 Diagnosed Patients With P450 Oxidoreductase Deficiency
}

\author{
Huiying Sun \\ Beijing KingMed \\ Shenggen Hou \\ Beijing KingMed \\ Xujing Kong \\ Beijing KingMed \\ Xiaomin Fan \\ Beijing KingMed \\ Zheng Zhai ( $\nabla$ zhaizheng@bjmu.edu.cn ) \\ Peking University Health Science Center \\ Yanhua Zheng \\ Beijing KingMed \\ Baorong Chen \\ Beijing Aerospace General Hospital
}

\section{Research Article}

Keywords: Congenital adrenal hyperplasia, P450 oxidoreductase deficiency (PORD), steroid hormones, liquid chromatography-tandem mass spectrometry (LC-MS/MS)

Posted Date: September 23rd, 2021

DOI: https://doi.org/10.21203/rs.3.rs-903045/v1

License: @ (i) This work is licensed under a Creative Commons Attribution 4.0 International License. Read Full License 


\section{Abstract}

Purpose: Diagnostic of congenital adrenal hyperplasia (CAH) patients with P450 oxidoreductase deficiency (PORD) subtype is a difficult task as biochemical monitoring criteria is not well defined. For the identification of steroid hormone biomarkers in plasma to diagnose PORD.

Methods: Study of the steroid hormone metabolic pathway, a novel method for the determination of 19 steroid hormone were established based on liquid chromatography-tandem mass spectrometry (LC-MS/MS). The measurement of 19 steroid hormones in plasma samples of clinical patients and normal reference population was carried out. A total of 9 clinically diagnosed patients ( 3 males, 6 females) with PORD were enrolled in the study.

Results: In 9 patients with PORD, plasma pregnenolone, 17-hydroxyprogesterone, corticosterone, 11-deoxycorticosterone, 11-deoxycortisol, and 21deoxycortisol, were significantly $(\mathrm{P}<0.001)$ increased when compared with those of the normal control group at the initial diagnosis of PORD. The concentrations of androstenedione, testosterone, dihydrotestosterone, dehydroepiandrosterone sulfate and estradiol in male patients with PORD were significantly $(P<0.001)$ lower than those in control group. There were significant $(P<0.001)$ differences between the female patients with $P O R D$ and the control group in the concentration of dihydrotestosterone and dehydroepiandrosterone sulfate.

Conclusion: Pregnenolone, 17-hydroxyprogesterone, corticosterone, 11-deoxycorticosterone, 11-deoxycorticosteroid, 21-deoxycorticosteroid, androstenedione, testosterone, dihydrotestosterone, dehydroepiandrosterone, estradiol, and the ratio of testosterone to dihydrotestosterone are important markers in the diagnosis of PORD.

\section{Highlights}

- P450 oxidoreductase deficiency (PORD) is a rare type of congenital adrenal hyperplasia (CAH).

- A novel LC-MS/MS method was introduced to measure 19 steroids in plasma

- Key biochemical markers were found to diagnose and evaluate PORD.

\section{Introduction}

Congenital adrenal hyperplasia (CAH) is an inherited metabolic disorder, manifests a range of clinical phenotypes, associated with a number of morbidity and mortality in both affected children and adults, resulting in a series of hormonal imbalances in adrenal steroidogenesis of glucocorticoid, mineralocorticoid and sexual steroid hormone production ${ }^{1-3}$. Previously, the most common cause of CAH was ascribed to 21 -hydroxylase deficiency, which account for $90-95 \%$ of CAH patients, followed by some other less frequent deficiency of $11 \beta$-hydroxylase, 17 a-hydroxylase/17,20-lysae and $3 \beta$-hydroxysteroid dehydrogenase. The typical symptoms of CAH were salt-wasting and sex development disorder. Deprivation of cortisol and aldosterone causing salt-wasting with severe dehydration, hypertension, hyponatremic, hyperkalemia, polyuria and hyperpigmentation ${ }^{4,5}$. Disorder of sex development was the consequence of abnormal production of sex hormones, appeared as ambiguous genitalia, external genitalia development abnormality, menstrual irregularities and infertility in women ${ }^{6}$, 7. 17-hydroxyprogesterone was the major criteria in early $\mathrm{CAH}$ screening, nevertheless, it was insufficient to distinguish the complex classification of $\mathrm{CAH}^{8}$. A comprehensive biochemical assay is needed to target the abnormal hormone synthesis segment.

P450 oxidoreductase deficiency (PORD) was a rare case in CAH patients. The gene of P450 oxidoreductase is located on chromosome 7q11,2, composed of $32 \mathrm{~kb}$ gene containing 15 exons, encoding the an $82 \mathrm{kDa}$ endoplasmic reticulum membrane-bound protein with 680 residues $^{9}$. P450 oxidoreductase protein comprises of four domains, NADPH, FAD, FMN binding domains and a hinge region. Two electrons from NADPH are transferred sequentially via FAD and FMN, and eventual transfer to electron accepting microsomal CYP enzyme. Disruption of P450 oxidoreductase should affect all of cytochrome P450 enzymes receive electrons from NADPH through it, known as CYP17A1, CYP21A2 and CYP19A1, brought about congenital malformation like skeletal deformities, disorder of sex development and CAH related syndromes.

Such complicated diagnostic paradigm for PORD requires characterization of rare deficits in several steroid metabolic pathways with accurate and specific method $^{10-12}$. Several recent studies have demonstrated that liquid chromatography-tandem mass spectrometry (LC-MS/MS) should be routine method and good standard for the definition of CAH compared to immunoassay ${ }^{13-17}$. LC-MS/MS protocols not only showed excellent sensitivity and specificity but also characterized much more steroids in a short run times, which made it possible to carry out an overall screening for steroidogenesis profiles.

Herein, we applied a LC-MS/MS method for the detection of 19 steroids in biochemical diagnosing PORD. In the case of 9 diagnosed PORD, significant changes of hormones were reported.

\section{Material \& Method}

\subsection{Reagent \& Material}

Nineteen steroid standards, including pregnenolone (PREG), 17-hydroxypregnenolone (17-OHP), 21-deoxycortisol (21-DOC), dehydroepiandrosterone (DHEA) were purchased form Cambridge; corticosterone (CORT), aldosterone (ALDO), 17-hydroxyprogesterone (17-OHPREG), cortisol (F), estrone (E) were obtained form TRC; cortisone, androstenedione (AD), testosterone (T), estradiol (E2) were brought from Dr. Ethrenstorefer; 11-deoxycorticosterone (11-DOC) and 11deoxycortisol (11-DOF) were from IsoSciences; dihydrotestosterone (DHT) was purchased from Cerlliant; dehydroepiandrosterone sulfate (DHEAS) was purchased from Medical Isotopes; progesterone (P) and estriol (E3) were purchased from National Institute of Metrology of China. Nineteen steroid isotopes 
internal standards consisted of pregnenolone-D4, 17-hydroxypregnenolone-D2 C2, 21-deoxycortisol-D8, estradiol-D4, estriol-D3 were purchased from Cambridge; corticosterone-D8, cortisol-D4, cortisone-D8 were obtained from TRC; 11-deoxycorticosterone-D8, dehydroepiandrosterone sulfate-D6, estrone-D4 were brought from Medical Isotopes; progesterone-D9 and testosterone-C3 were purchased from Cerlliant; androstenedione-C3 and dihydrotestosterone were purchased from Sigma; aldosterone-D7, 11-deoxycortisol-D5, dehydroepiandrosterone-D6 were purchased from IsoSciences; 17-hydroxyprogesterone-D8 was purchased from CNM. LC-MS/MS grade methanol, acetonitrile, hexane were from Merck; $\mathrm{NH}_{4} \mathrm{~F}$ was brought from Sigma, deionized water was prepared with Milli-Q system.

\subsection{Subjects \& sample preparation}

Nine clinically diagnosed PORD patients' whole bloods were withdrew before hormone treatment. Results of normal people were collected from 318 healthy volunteers of 116 females and 202 males. The whole blood was centrifuged $1000 \mathrm{~g}$ for $5 \mathrm{~min}$, plasma was separated and storage at $-80^{\circ} \mathrm{C}$ before analysis. $100 \mu \mathrm{L}$ plasma sample was added in $1.5 \mathrm{~mL}$ tube with $10 \mu \mathrm{L}$ internal standards, then $150 \mu \mathrm{L}$ methanol was added to precipitated protein, followed by vortex mixing and further put in $200 \mu \mathrm{L}$ water and mixed well. The treated samples were centrifuged $12000 \mathrm{rpm}$ for $15 \mathrm{~min}$ at $4^{\circ} \mathrm{C}$. While Waters Qasis ${ }^{\circledR}$ PRiME $\mathrm{HLB}$ $\mu$ Elution solid phase extraction (SPE) cartridge was activated by $200 \mu \mathrm{L}$ methanol and $200 \mu \mathrm{L}$ pure water through Waters positive pressure device, before $375 \mu \mathrm{L}$ supernatant of each sample was loaded on the plate. Afterwards, $200 \mu \mathrm{L} 10 \%$ acetonitrile and $200 \mu \mathrm{L}$ hexane were used to elute impurity substance in samples with positive pressure. At last, $40 \mu \mathrm{L} 90 \%$ acetonitrile was applied to elute analyte steroids on solid phase column and mixed with $60 \mu \mathrm{L}$ water in collection 96 well plates. Standard curve samples were prepared with $10 \mu \mathrm{L}$ standard materials solution, $10 \mu \mathrm{L}$ internal standards and diluted with $90 \mu \mathrm{L}$ water before the same SPE procedure.

\subsection{LC-MS/MS conditions}

Sample steroids separation was accomplished by Waters ACQUITY Ultra Performance Liquid Chromatography on Water BEH C8, 2.1*100mm, 1.7 $\mu \mathrm{m}$ column. $20 \mu \mathrm{L}$ samples was injected and the column was kept at $50^{\circ} \mathrm{C}$, eluted with a binary mobile phase of water containing $0.5 \mathrm{mM} \mathrm{NH} \mathrm{H}_{4} \mathrm{~F}(\mathrm{phase} \mathrm{A})$ and methanol (phase B), the solvent gradient program was optimized as follows in Table 1. Eluent was analyzed with Waters TQ-S triple quadrupole mass spectrometry equipped with electrospray ionization source. ESI + mode was selected for PREG, P, 11-DOC, CORT, 17-OHP, 11-DOF, 21-DOF, F, cortisone, DHEA and AD. ESImode was applied in the detection of ALDO, 17-OHPREG, DHEAS, E, E2 and E3. The parameters for ion source were set at: capillary voltage 2.8kV for ESI + and $2.4 \mathrm{kV}$ for ESI-, source offset voltage $50 \mathrm{~V}$, desolvation temperature $600^{\circ} \mathrm{C}$, desolvation gas $1100 \mathrm{~L} / \mathrm{Hr}$, cone gas $150 \mathrm{~L} / \mathrm{Hr}$, Nebuliser pressure 7 bar. The multiple reaction monitoring mode was chose to quantify steroids, for each compounds the parameters were listed in Table. 2.

\subsection{Statistical method}

The box-plot and scatter plot of 19 steroid hormone and ratio results were plotted by R4.0.1 software. Significant results were verified by Wilcoxon test.

\section{Result}

\subsection{Hormone abnormal in patient with PORD}

The concentration of 19 steroid hormones in plasma were detected through LC-MS/MS method described beforehand. Test results of 9 patient diagnosed with PORD in their initial consultation, were listed in table. 3. It showed that these 19 steroid hormones indicators presented three different variations in 9 patients with PORD compared to normal people (Fig. 1). Firstly, 6 of 19 hormones, such as pregnenolone, 17-hydroxyprogesterone, corticosterone, 11deoxycorticosterone, 11-deoxycortisol, and 21-deoxycortisol were significantly $(P<0.001)$ increased compared to those of the normal control. Secondly, the concentrations of 17-hydroxypregnenolone and aldosterone were augmented less significantly $(0.001<P<0.05)$. By contrast, the concentrations of dehydroepiandrosterone, progesterone, estrone, estriol, cortisol and cortisone were approximate among patients and normal people, with no significant $(\mathrm{P}>$ 0.05) difference between the two groups (Fig. 2).

\subsection{Hormone difference between male and female patient with PORD}

Next we evaluated the sexual diversity of steroid hormones in patients with PORD and normal people (Fig. 3). Specifically, the concentrations of androstenedione, testosterone, dihydrotestosterone, dehydroepiandrosterone sulfate and estradiol in male patients with $P O R D$ were significantly $(P<0.001)$ declined contrast to control group. While in female patients, the level of dihydrotestosterone and dehydroepiandrosterone sulfate were significantly $(P<0.001)$ lower than control group, however, no significant $(P>0.05)$ difference was found in androstenedione, testosterone and estradiol between female patient and referential population. Moreover, the ratios of testosterone to dihydrotestosterone in male patients with PORD were significantly $(P<0.001)$ decreased, on the other hand, that ratios of female patients were slightly raised with no significant $(P>0.05)$ (Fig. 4).

\subsection{Case report-phenotype $\&$ genotype of patient 6}

To further elucidate the pathogenesis and clinical outcome of PORD, we collected the case report of patient 6 with integral gene analysis as an example. This 7 years old male patient was hospitalized with the symptom of short penis, undescended testis and multiple joints restrict of motion. He was well-nourished with $\mathrm{BMI}$ of $20.65 \mathrm{~kg} / \mathrm{m}^{2}(\mathrm{H} 126.4 \mathrm{~cm}$, Wt $33 \mathrm{~kg})$. Clinical examination revealed the abnormal morphology of external genitalia and skeleton, including vulva mold, small penis $\left(\mathrm{P} 0.5^{\star} 0.5 \mathrm{~cm}\right)$, lower urethral orifice, empty bilateral scrotum, cryptorchid inguinal testis and bilateral testes were small $(<1 \mathrm{~mL})$ and calcified, together with limited external rotation of both wrists and extension of the metacarpophalangeal joint, slight lateral curvature of crista, asymmetry of both lower limbs, left lower limb was $1 \mathrm{~cm}$ thicker than right one, limited ankle dorsiflexion and plantar-flexion, shortened 4,5th metatarsal bones and mild fatty liver. Our test measured the patient's 19 steroid hormones in plasma which demonstrated that: 1. in progesterone metabolic pathway, pregnenolone, progesterone, 17-hydroxyprogesterone and 17-hydroxyprogesterone were elevated; 2. in mineralocorticoid metabolic pathway, deoxycorticosterone and corticosterone were 
elevated and aldosterone was normal; 3 . in glucocorticoid metabolic pathway, the levels of cortisol decreased, while 21-deoxycortisol significantly increased; 4. in the androgen synthesis pathway, concentration of dehydroepiandrosterone sulfate decreased; 5 . Each hormone in the estrogen metabolic pathway was normal. Besides, gene sequence was performed in patient as well as his parents (Fig. 5), where complex heterozygous variation of P450 oxidoreductase gene was found in the patient, the combined mutation of 1370G > A (R457H) and 1660G > T (R554X). According to Sanger's verification, patient's father carried $1370 \mathrm{G}>\mathrm{A}$ mutation, the heterozygous variation of $1660 \mathrm{G}>\mathrm{T}$ was found in the mother.

\section{Discussion}

PORD originated CAH was used to be overlooked, since a CAH clinical entity with combined 17a-hydroxylase (CYP17A1) and 21-hydroxylase (CYP21A2) deficiency was first described in 1985. Initially, research suggested that the disorder would be caused by concurrent mutations in both CYP17 and CYP21 genes, mainly based on obvious biochemical evidence for the impair of 17a-hydroyxlase and 21-hydroxylase activities in affected patient. With the progress of gene analysis, coding sequences of CYP17A1 and CYP21A2 in those failed to reveal any mutations. Only until 2004, PORD was first discovered, several individual groups reported that this disease could be due inactivated P450 oxidoreductase, which served as a key electron donor to provide electrons to all microsomal P450 (CYP) enzymes in steroid synthesis, especially, CYP17 and CYP2 $1^{18}$ (Fig. 6). This founding strikingly highlights the importance role of P450 oxidoreductase in controlling the redox potential for steroidogenesis, meanwhile uncovered a novel pathogenesis of $\mathrm{CAH}$.

The biochemical phenotype of PORD was similar to partial deficiency of 17-hydroxylase and 21-hydroxylase activities in various combination, since it was required for both enzymes to be functional. The steroidogenesis starts from the substrate of cholesterol toward glucocorticoids, mineralocorticoids and sexual steroids. CYP17 exerts both 17a-hydroxylase and 17,20-lyase activities, the former catalyzes pregnenolone and progesterone to 17-hydroxypregnenolone and 17-hydroxyprogesterone, the latter further catalyze them to dehydroepiandrosterone and androstenedione, respectively. As the 17,20-lyase reaction activity is more sensitive to the interaction of P450 oxidoreductase than 17a-hydroxylase reaction, in case of PORD, the formation of dehydroepiandrosterone and androstenedione were blocked, with the accumulation of pregnenolone, progesterone and 17-hydroxyprogesterone. In accordance with our finding that plasma concentration of progesterone, 17-hydroxyprogesterone, pregnenolone were elevated in PORD patient.

In contrast to classical 21-hydroxylase deficiency in CAH, PORD triggered 21-hydroxylase inhibition give rise to mineralocorticoid and glucocorticoid precursors accumulation rather than depletion, due to preferential 17-hydroxylase inhibition over 21-hydroxylase inhibition. Taken our results into condensation, it again supported that the plasma level of 11-deoxycorticosterone, corticosterone, aldosterone and 11-deoxycorticosterone, 11-deoxycortisol and 21-deoxycortisol were ascended.

Converse to classic 21-hydroxylase deficiency form of CAH, PORD affected patients circulating androgen are lower in both sexes. Disordered sex development were found in male and female patients, affected boys grow the symptom of undervirilized, micropenis or malformation of urethra ${ }^{19}$. Phenotypically, affected girls may present prenatal virilization of external genitalia, hence no progressive virilization ever since, which could be explained by the only existence of alternative androgen synthesis pathway in fetal period contributed to prenatal virilization, but ceasing androgen shortly after birth. Consist to our results, affected boys manifested sharply decreased level of androgen, such as androstenedione, testosterone, dihydrotestosterone and dehydroepiandrosterone, yet undervirilized biomarkers in female patient was less clear. In addition, the activity of CYP19A1 was also hampered in PORD, leading to the prevention of product estrone and estradiol synthesized from androstenedione and testosterone, which match our results that estradiol was decreased in male PORD patients. In general, sex steroid hormone are lower in PORD patient.

In the case diagnosed patient 6 , undervirilized symptoms were depicted by malformation of external genitalia, with unambiguously decreased androgen and increased mineralocorticoid steroid biomarkers ${ }^{20}$. Apart from that, skeletal abnormalities observed in patient 6 suggested that the patient may also suffered from Antley-Bixler syndrome, whose pathophysiology remains to be expounded ${ }^{21,22}$. So far, it suggested that the impairment of P450 oxidoreductasedependent CYP51A1 in steroid biosynthesis could be accountable for skeletal malformations ${ }^{20}$. Besides, POR also serves as indispensable electron donor to many hepatic CYP enzymes in metabolism and detoxification, therefore PORD in patient 6 may have impact on hepatic CYP enzyme to some extent and developed fatty liver ${ }^{23}$. Eventually, gene sequencing proved the diagnosis of PORD, in which pateral $1370 \mathrm{G}>\mathrm{A}(\mathrm{R} 457 \mathrm{H})$ mutations and materal $1660 \mathrm{G}>\mathrm{T}$ (R554X) mutations of POR gene were found in patient 6 . The R457H was the most frequent disease-causing mutation in Japanese populations ${ }^{24}$, and has been reported that $\mathrm{R} 457 \mathrm{H}$ yields almost no activity for 17,20 -lyase and only $1-3 \%$ activities for 17 -hydroxylase and $\mathrm{P} 450$ aromatase. This mutation located in the FAD binding domain of P450 oxidoreductase, guanidinium group of the wild type residue R457 tends to form a salt bridge with FAD, alternatively, mutated H457 weakens the interaction ${ }^{25}, 26$. R554X mutation located in NADPH binding domain of P450 oxidoreductase, causing the 554th encoding amino acid switched from Arginine to terminator, which may induce protein truncation or activate nonsense-mediated mRNA degradation, thus affecting the function of protein encoded by the gene. In this case report, genotype and biochemical results provided reliable explanation for the impaired activity of P450 oxidoreductase, in turn, elicit the corresponding phenotype.

\section{Conclusion}

In this study, harnessing the advance of LC-MS/MS technology, we established and reported a robust method monitored a panel of 19 steroid hormones to diagnose and evaluate PORD by biochemical screening. Remarkably, we discovered significant elevated markers, including pregnenolone, 17hydroxyprogesterone, corticosterone, 11-deoxycorticosterone, 11-deoxycortisol, and 21-deoxycortisol; as well as significant decreased markers, such as androstenedione, testosterone, dihydrotestosterone, dehydroepiandrosterone sulfate and estradiol in patient with PORD. Compared to traditional immunoassay with limited items, we greatly expanded the detection scope of hormones in one test, which will certainly facilitate the precise diagnose of PORD among other types of $\mathrm{CAH}$. Together with gene sequence, misdiagnosis will be avoided and a definite spectrum of steroidomics can be present for better treatment of PORD patients in the future. 


\section{Abbreviations}

CAH (congenital adrenal hyperplasia), PORD (P450 oxidoreductase deficiency), LC-MS/MS (liquid chromatography-tandem mass spectrometry), PREG (pregnenolone), P (progesterone), 17-OHP (17-hydroxypregnenolone), 17-OHPREG (17-hydroxyprogesterone), 21-DOC (21-deoxycortisol), 11-DOC (11deoxycorticosterone), 11-DOF (11-deoxycortisol), ALDO (aldosterone), F (cortisol), DHEA (dehydroepiandrosterone), DHEAS (dehydroepiandrosterone sulfate), CORT (corticosterone), E/E1 (estrone), E2 (estradiol), E3 (estriol), AD (androstenedione), T (testosterone), DHT (dihydrotestosterone).

\section{Declarations}

\section{Declaration of competing interest}

The authors have nothing to disclose.

\section{References}

1. El-Maouche, D.; Arlt, W.; Merke, D. P., Congenital adrenal hyperplasia. The Lancet 2017, 390 (10108), 2194-2210.

2. Merke, D. P.; Bornstein, S. R., Congenital adrenal hyperplasia. The Lancet 2005, 365 (9477), 2125-2136.

3. Miller, W. L.; Auchus, R. J., The molecular biology, biochemistry, and physiology of human steroidogenesis and its disorders. Endocr Rev 2011, 32 (1), 81151.

4. Falhammar, H.; Wedell, A.; Nordenstrom, A., Biochemical and genetic diagnosis of 21-hydroxylase deficiency. Endocrine 2015, 50 (2), $306-14$.

5. Ghayee, H. K.; Auchus, R. J., Basic concepts and recent developments in human steroid hormone biosynthesis. Rev Endocr Metab Disord 2007, 8 (4), 289300.

6. Trakakis, E.; Basios, G.; Trompoukis, P.; Labos, G.; Grammatikakis, I.; Kassanos, D., An update to 21-hydroxylase deficient congenital adrenal hyperplasia. Gynecol Endocrinol 2010, 26 (1), 63-71.

7. Idkowiak, J.; Malunowicz, E. M.; Dhir, V.; Reisch, N.; Szarras-Czapnik, M.; Holmes, D. M.; Shackleton, C. H.; Davies, J. D.; Hughes, I. A.; Krone, N.; Arlt, W., Concomitant mutations in the P450 oxidoreductase and androgen receptor genes presenting with 46,XY disordered sex development and androgenization at adrenarche. J Clin Endocrinol Metab 2010, 95 (7), 3418-27.

8. White, P. C., Neonatal screening for congenital adrenal hyperplasia. Nat Rev Endocrinol 2009, $5(9), 490-8$.

9. Miller, W. L.; Huang, N.; Pandey, A. V.; Fluck, C. E.; Agrawal, V., P450 oxidoreductase deficiency: a new disorder of steroidogenesis. Ann N Y Acad Sci 2005, 1061, 100-8.

10. Nimkarn, S.; New, M. I., Prenatal diagnosis and treatment of congenital adrenal hyperplasia owing to 21-hydroxylase deficiency. Nat Clin Pract Endocrinol Metab 2007, 3 (5), 405-13.

11. Nimkarn, S.; New, M. I., Prenatal diagnosis and treatment of congenital adrenal hyperplasia due to 21-hydroxylase deficiency. Mol Cell Endocrino/ 2009, $300(1-2), 192-6$

12. Oriolo, C.; Fanelli, F.; Castelli, S.; Mezzullo, M.; Altieri, P.; Corzani, F.; Pelusi, C.; Repaci, A.; Di Dalmazi, G.; Vicennati, V.; Baldazzi, L.; Menabo, S.; Dormi, A.; Nardi, E.; Brillanti, G.; Pasquali, R.; Pagotto, U.; Gambineri, A., Steroid biomarkers for identifying non-classic adrenal hyperplasia due to 21-hydroxylase deficiency in a population of PCOS with suspicious levels of 170H-progesterone. J Endocrinol Invest 2020, 43 (10), 1499-1509.

13. Zheng, Y.; Zhao, H.; Zhu, L.; Cai, Z., Comprehensive identification of steroid hormones in human urine based on liquid chromatography-high resolution mass spectrometry. Anal Chim Acta 2019, 1089, 100-107.

14. Stolze, B. R.; Gounden, V.; Gu, J.; Elliott, E. A.; Masika, L. S.; Abel, B. S.; Merke, D. P.; Skarulis, M. C.; Soldin, S. J., An improved micro-method for the measurement of steroid profiles by APPI-LC-MS/MS and its use in assessing diurnal effects on steroid concentrations and optimizing the diagnosis and treatment of adrenal insufficiency and CAH. J Steroid Biochem Mol Biol 2016, 162, 110-6.

15. Gao, W.; Kirschbaum, C.; Grass, J.; Stalder, T., LC-MS based analysis of endogenous steroid hormones in human hair. J Steroid Biochem Mol Bio/ 2016, $162,92-9$.

16. Keevil, B. G., LC-MS/MS analysis of steroids in the clinical laboratory. Clin Biochem 2016, 49 (13-14), 989-97.

17. Han, L.; Tavakoli, N. P.; Morrissey, M.; Spink, D. C.; Cao, Z. T., Liquid chromatography-tandem mass spectrometry analysis of 17-hydroxyprogesterone in dried blood spots revealed matrix effect on immunoassay. Anal Bioanal Chem 2019, 411 (2), 395-402.

18. Papadakis, G. E.; Dumont, A.; Bouligand, J.; Chasseloup, F.; Raggi, A.; Catteau-Jonard, S.; Boute-Benejean, O.; Pitteloud, N.; Young, J.; Dewailly, D., Nonclassic cytochrome P450 oxidoreductase deficiency strongly linked with menstrual cycle disorders and female infertility as primary manifestations. Hum Reprod 2020, 35 (4), 939-949.

19. Pan, P.; Zheng, L.; Chen, X.; Huang, J.; Yang, D.; Li, Y., Successful live birth in a Chinese woman with P450 oxidoreductase deficiency through frozen-thawed embryo transfer: a case report with review of the literature. J Ovarian Res 2021, 14 (1), 22.

20. Fukami, M.; Ogata, T., Cytochrome P450 oxidoreductase deficiency: rare congenital disorder leading to skeletal malformations and steroidogenic defects. Pediatr Int 2014, 56 (6), 805-808.

21. Fan, L.; Ren, X.; Song, Y.; Su, C.; Fu, J.; Gong, C., Novel phenotypes and genotypes in Antley-Bixler syndrome caused by cytochrome P450 oxidoreductase deficiency: based on the first cohort of Chinese children. Orphanet J Rare Dis 2019, 14 (1), 299.

22. Fluck, C. E.; Tajima, T.; Pandey, A. V.; Arlt, W.; Okuhara, K.; Verge, C. F.; Jabs, E. W.; Mendonca, B. B.; Fujieda, K.; Miller, W. L., Mutant P450 oxidoreductase causes disordered steroidogenesis with and without Antley-Bixler syndrome. Nat Genet 2004, 36 (3), 228-30. 
23. Arlt, W., P450 oxidoreductase deficiency and Antley-Bixler syndrome. Rev Endocr Metab Disord 2007, 8 (4), 301-7.

24. Fukami, M.; Nishimura, G.; Homma, K.; Nagai, T.; Hanaki, K.; Uematsu, A.; Ishii, T.; Numakura, C.; Sawada, H.; Nakacho, M.; Kowase, T.; Motomura, K.; Haruna, H.; Nakamura, M.; Ohishi, A.; Adachi, M.; Tajima, T.; Hasegawa, Y.; Hasegawa, T.; Horikawa, R.; Fujieda, K.; Ogata, T., Cytochrome P450 oxidoreductase deficiency: identification and characterization of biallelic mutations and genotype-phenotype correlations in 35 Japanese patients. $J$ Clin Endocrinol Metab 2009, 94 (5), 1723-31.

25. Xia, C.; Panda, S. P.; Marohnic, C. C.; Martasek, P.; Masters, B. S.; Kim, J. J., Structural basis for human NADPH-cytochrome P450 oxidoreductase deficiency. Proc Natl Acad Sci U S A 2011, 108 (33), 13486-91.

26. Sahakitrungruang, T.; Huang, N.; Tee, M. K.; Agrawal, V.; Russell, W. E.; Crock, P.; Murphy, N.; Migeon, C. J.; Miller, W. L., Clinical, genetic, and enzymatic characterization of P450 oxidoreductase deficiency in four patients. J Clin Endocrinol Metab 2009, 94 (12), 4992-5000.

\section{Tables}

Table 1

Gradient program for UPLC analysis

\begin{tabular}{|llllll|}
\hline Gradient & Time(min) & Flow rate $(\mathrm{mL} / \mathrm{min})$ & A phase \% & B phase \% & Curve \\
\hline Initial & 0 & 0.3 & 60 & 40 & Initial \\
\hline 2 & 0.5 & 0.3 & 60 & 40 & 6 \\
\hline 3 & 4 & 0.3 & 45 & 55 & 6 \\
\hline 4 & 6.5 & 0.3 & 25 & 75 & 6 \\
\hline 6 & 7.2 & 0.3 & 10 & 90 & 1 \\
\hline
\end{tabular}


Table 2

Compound parameters for MRM mass analysis

\begin{tabular}{|c|c|c|c|c|c|c|c|}
\hline Compound & Quantifier $\mathrm{m} / \mathrm{z}$ & $\begin{array}{l}\text { Collision energy } \\
(\mathrm{eV})\end{array}$ & $\begin{array}{l}\text { Cone voltage } \\
\text { (V) }\end{array}$ & Compound & Quantifier $\mathrm{m} / \mathrm{z}$ & $\begin{array}{l}\text { Collision energy } \\
(\mathrm{eV})\end{array}$ & $\begin{array}{l}\text { Cone voltage } \\
\text { (V) }\end{array}$ \\
\hline PREG & $\begin{array}{l}299.10> \\
281.06\end{array}$ & 20 & 30 & 11-DOF & $\begin{array}{l}347.30> \\
109.05\end{array}$ & 16 & 50 \\
\hline PREG-D4 & $\begin{array}{l}303.17> \\
159.16\end{array}$ & 20 & 30 & 11-DOF-D5 & $\begin{array}{l}352.30> \\
100.02\end{array}$ & 22 & 50 \\
\hline$P$ & $\begin{array}{l}315.30> \\
109.02\end{array}$ & 10 & 50 & 21-DOF & $\begin{array}{l}347.27> \\
311.23\end{array}$ & 14 & 50 \\
\hline P-D9 & $\begin{array}{l}324.36> \\
100.05\end{array}$ & 20 & 50 & 21-DOF-D8 & $\begin{array}{l}355.33> \\
319.23\end{array}$ & 16 & 50 \\
\hline 11-DOC & $\begin{array}{l}331.30> \\
109.06\end{array}$ & 15 & 40 & $\mathrm{~F}$ & $\begin{array}{l}363.30> \\
327.19\end{array}$ & 7 & 50 \\
\hline 11-DOC-D8 & $\begin{array}{l}339.36> \\
100.02\end{array}$ & 22 & 40 & F-D4 & $\begin{array}{l}367.33> \\
121.08\end{array}$ & 24 & 50 \\
\hline CORT & $\begin{array}{l}347.30> \\
121.08\end{array}$ & 18 & 50 & $A D$ & $\begin{array}{l}287.30> \\
109.06\end{array}$ & 13 & 50 \\
\hline CORT-D8 & $\begin{array}{l}355.30> \\
125.05\end{array}$ & 24 & 58 & AD-C3 & $\begin{array}{l}292.30> \\
100.05\end{array}$ & 20 & 50 \\
\hline ALDO & $\begin{array}{l}359.23> \\
189.11\end{array}$ & 18 & 20 & $\mathrm{~T}$ & $\begin{array}{l}289.30> \\
109.08\end{array}$ & 12 & 50 \\
\hline ALDO-D8 & $\begin{array}{l}367.30> \\
194.11\end{array}$ & 16 & 20 & $\mathrm{~T}-\mathrm{C} 3$ & $\begin{array}{l}292.30> \\
100.05\end{array}$ & 20 & 50 \\
\hline 17-OHPREG & $\begin{array}{l}331.08> \\
287.16\end{array}$ & 20 & 50 & DHT & $\begin{array}{l}291.30> \\
255.28\end{array}$ & 16 & 50 \\
\hline $\begin{array}{l}\text { 17-OHPREG-D2 } \\
\text { C2 }\end{array}$ & $\begin{array}{l}335.08> \\
289.21\end{array}$ & 20 & 50 & DHT-C3 & $\begin{array}{l}294.30> \\
258.21\end{array}$ & 14 & 50 \\
\hline 17-OHP & $331.30>97.04$ & 15 & 40 & $E$ & $\begin{array}{l}269.20> \\
145.04\end{array}$ & 38 & 40 \\
\hline 17-OHP-D8 & $\begin{array}{l}339.33> \\
100.09\end{array}$ & 25 & 40 & E-D4 & $\begin{array}{l}273.20> \\
147.06\end{array}$ & 36 & 40 \\
\hline Cortisone & $\begin{array}{l}361.23> \\
121.04\end{array}$ & 32 & 50 & E2 & $\begin{array}{l}271.04> \\
183.06\end{array}$ & 40 & 30 \\
\hline Cortisone-D8 & $\begin{array}{l}369.36> \\
169.15\end{array}$ & 24 & 50 & E2-D4 & $\begin{array}{l}275.10> \\
147.14\end{array}$ & 40 & 40 \\
\hline DHEA & $\begin{array}{l}271.23> \\
213.20\end{array}$ & 15 & 40 & E3 & $\begin{array}{l}287.04> \\
171.06\end{array}$ & 35 & 50 \\
\hline DHEA-D6 & $\begin{array}{l}277.16> \\
219.12\end{array}$ & 16 & 40 & E3-D3 & $\begin{array}{l}290.05> \\
173.09\end{array}$ & 35 & 50 \\
\hline DHEAS & $367.17>80.00$ & 62 & 50 & & & & \\
\hline DHEAS-D6 & $373.23>98.00$ & 32 & 50 & & & & \\
\hline
\end{tabular}


Table 3

PORD patients' information and concentration of 19 steroids measured by LC-MS/MS

\begin{tabular}{|c|c|c|c|c|c|c|c|c|c|c|c|c|c|c|c|}
\hline Patient & Sex & Age & $\begin{array}{l}\text { PREG } \\
\mathrm{pg} / \mathrm{mL}\end{array}$ & $\begin{array}{l}\mathrm{P} \\
\mathrm{ng} / \mathrm{mL}\end{array}$ & $\begin{array}{l}\text { 11- } \\
\text { DOC } \\
\mathrm{pg} / \mathrm{mL}\end{array}$ & $\begin{array}{l}\text { CORT } \\
\mathrm{ng} / \mathrm{mL}\end{array}$ & $\begin{array}{l}\text { ALD } \\
\mathrm{pg} / \mathrm{ml}\end{array}$ & $\begin{array}{l}17- \\
\text { OHPREG } \\
\mathrm{ng} / \mathrm{mL}\end{array}$ & $\begin{array}{l}\text { 17- } \\
\text { OHP } \\
\text { ng/mL }\end{array}$ & $\begin{array}{l}\text { 11- } \\
\text { DOF } \\
\mathrm{pg} / \mathrm{mL}\end{array}$ & $\begin{array}{l}\text { 21- } \\
\text { DOF } \\
\mathrm{pg} / \mathrm{mL}\end{array}$ & $\begin{array}{l}\mathrm{F} \\
\mathrm{ng} / \mathrm{mL}\end{array}$ & $\begin{array}{l}\text { Cortisone } \\
\mathrm{ng} / \mathrm{mL}\end{array}$ & $\begin{array}{l}\text { DHEA } \\
\mathrm{ng} / \mathrm{mL}\end{array}$ & $\begin{array}{l}\mathrm{DH} \\
\mathrm{ng}\end{array}$ \\
\hline 1 & $M$ & 9 & 63.0 & 0.08 & 40.8 & 0.4 & 21.3 & 0.1 & 0.1 & 8.0 & 6.2 & 191.6 & 67.6 & 0.0 & 21. \\
\hline 2 & $\mathrm{M}$ & 16 & 2618.5 & 0.48 & 335.9 & 25.1 & 86.2 & 5.4 & 1.5 & 1313.3 & 196.9 & 155.9 & 17.9 & 5.4 & $14 i$ \\
\hline 3 & $\mathrm{~F}$ & 13 & 1819.0 & 19.11 & 329.0 & 12.2 & 140.1 & 2.3 & 5.1 & 248.3 & 573.8 & 27.9 & 7.1 & 0.2 & 66. \\
\hline 4 & $\mathrm{~F}$ & 30 & 7861.8 & 8.78 & 661.2 & 29.5 & 595.9 & 3.4 & 7.0 & 466.7 & 808.6 & 35.7 & 5.7 & 0.4 & 36. \\
\hline 5 & $\mathrm{~F}$ & 29 & 6514.5 & 2.80 & 321.1 & 19.3 & 44.6 & 5.2 & 2.9 & 734.9 & 1023.9 & 97.6 & 14.3 & 1.7 & $93 i$ \\
\hline 6 & $M$ & 7 & 13627.1 & 93.64 & 1641.1 & 38.3 & 46.9 & 4.0 & 28.7 & 552.9 & 3569.1 & 41.1 & 8.6 & 0.2 & 51. \\
\hline 7 & $\mathrm{~F}$ & 29 & 7480.5 & 1.69 & 564.8 & 39.4 & 89.7 & 12.8 & 3.6 & 2101.3 & 809.5 & 234.9 & 28.5 & 12.4 & 21 . \\
\hline 8 & $\mathrm{~F}$ & 34 & 4967.4 & 11.28 & 347.3 & 29.1 & 371.9 & 4.2 & 2.2 & 1386.1 & 70.4 & 123.3 & 26.8 & 4.1 & 11: \\
\hline 9 & $\mathrm{~F}$ & 28 & 19361.5 & 5.27 & 266.9 & 34.9 & 96.6 & 11.2 & 6.5 & 492.5 & 2132.1 & 131.9 & 19.6 & 2.1 & 131 \\
\hline
\end{tabular}

\section{Figures}

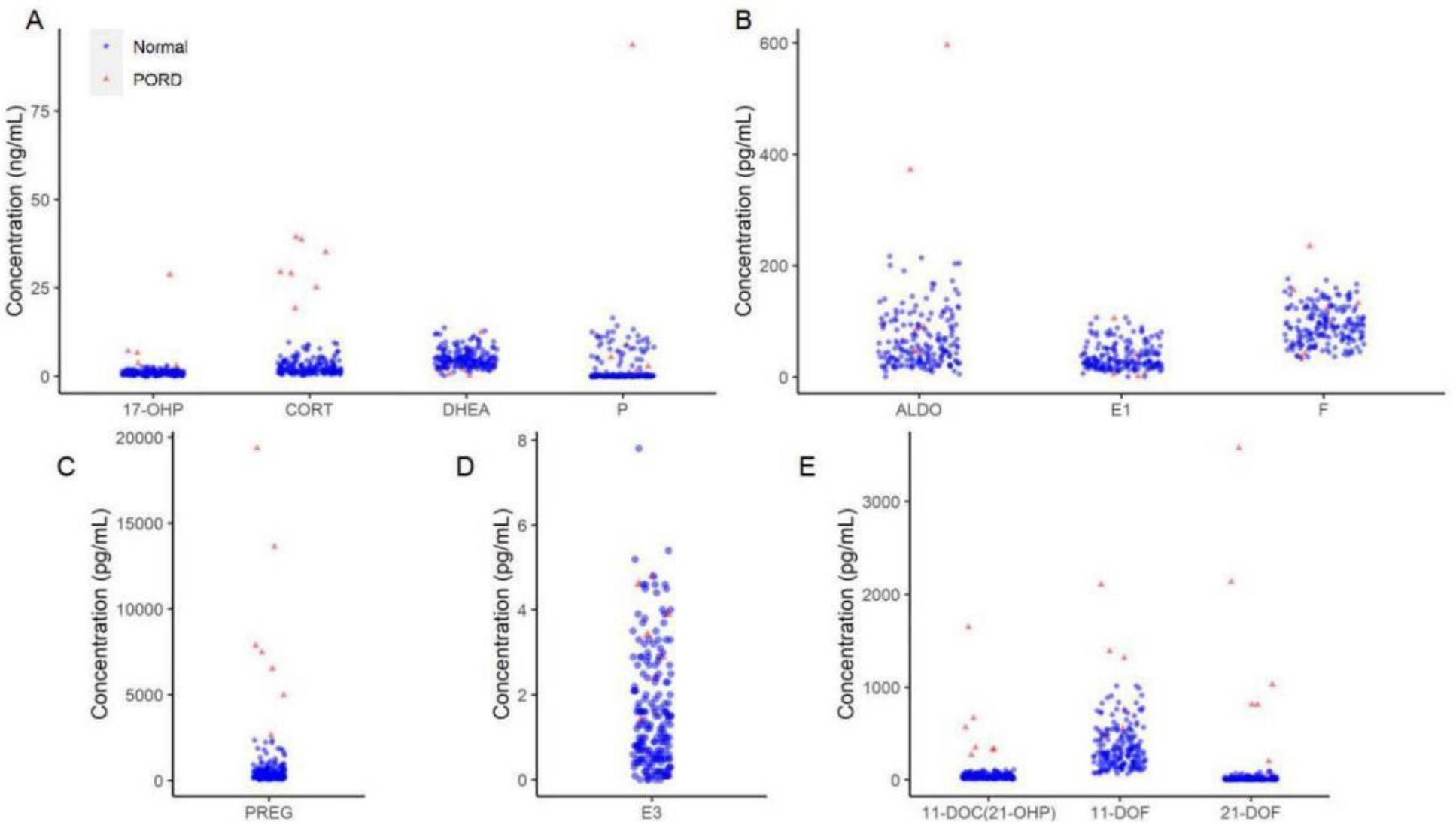

Figure 1

Scatter plot of steroid concentrations between PORD patient and normal people 


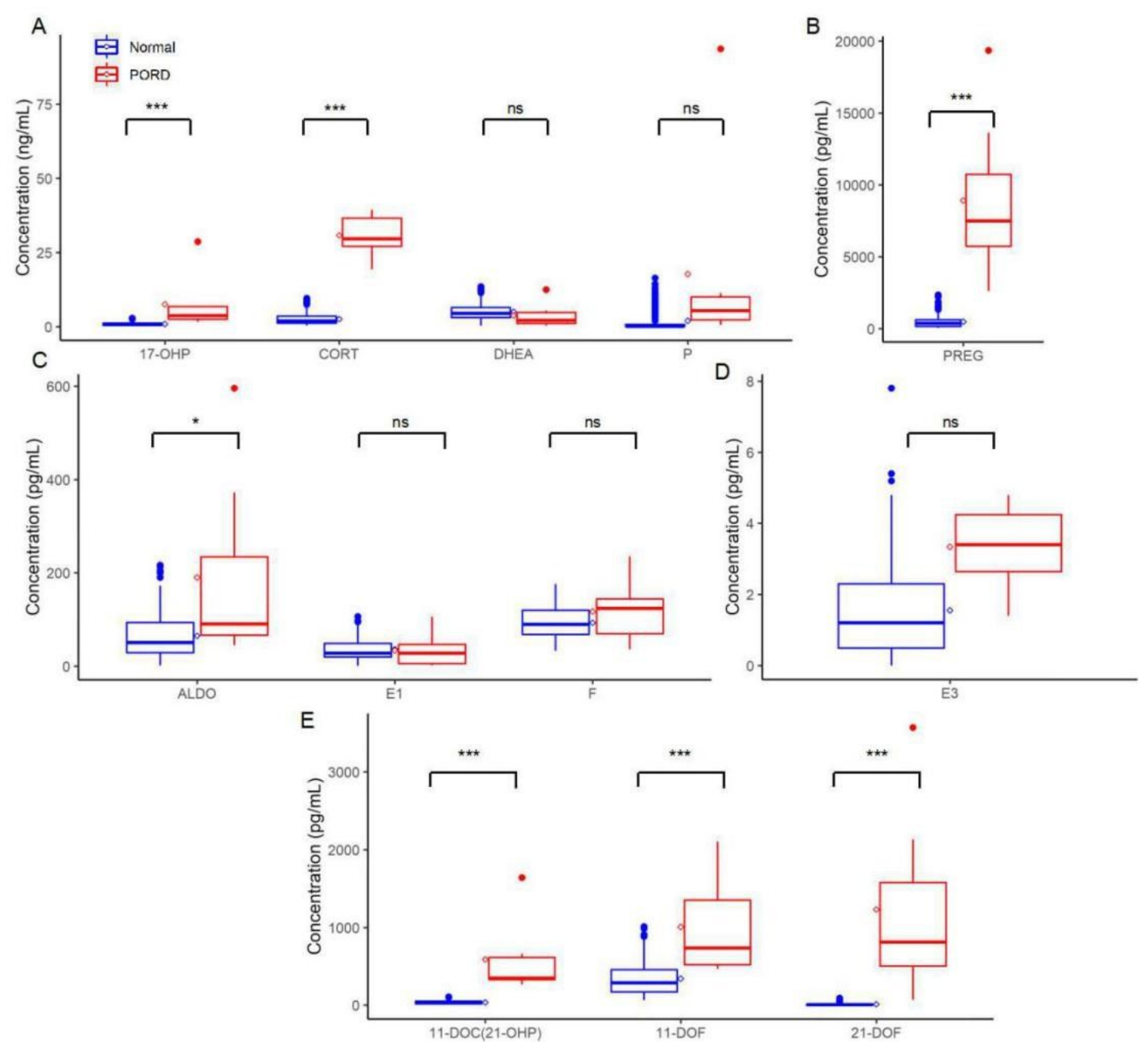

Figure 2

Box plot of steroid concentrations of PORD patient and normal people with $95 \%$ confidence interval. $* \star * ~ P<0.001, * 0.001<P<0.05, n s \mathrm{P}>0.05$. 
A
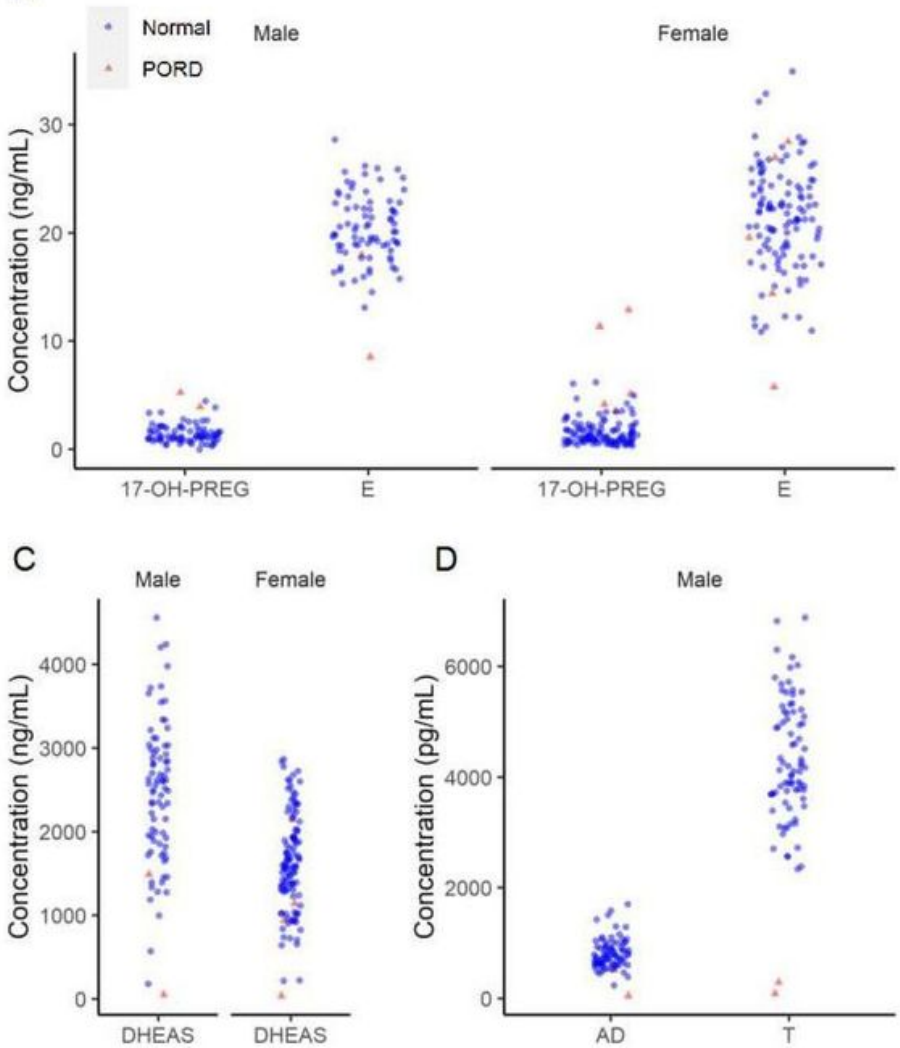

B

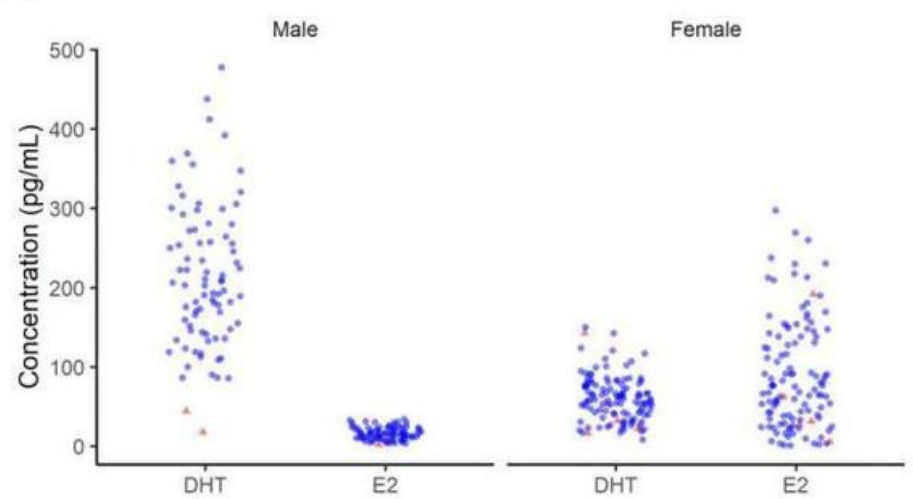

$\mathrm{E}$
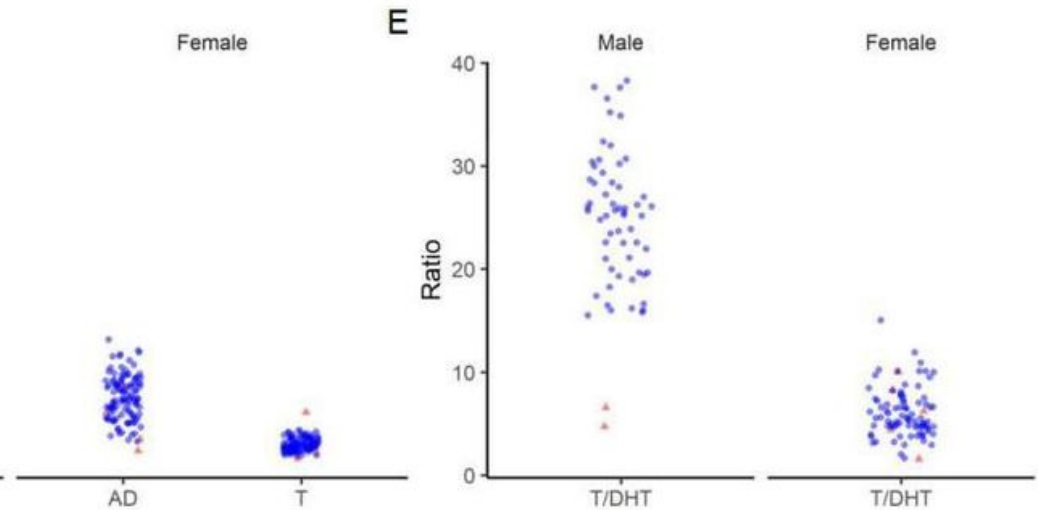

Figure 3

Scatter plot of steroid concentrations between PORD patient and normal people of both sexes. 




Figure 4

Box plot of steroid concentrations of PORD patient and normal people in both sexes with $95 \%$ confidence interval. ${ }^{* * *} P<0.001,{ }^{*} 0.001<P<0.05$, ns $P>0.05$.

A

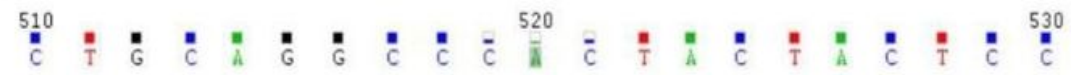

Patient 1370G>A

( R457H

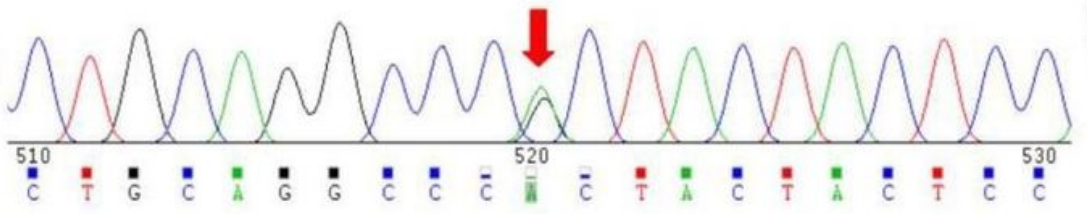

Paternal

$1370 \mathrm{G}>\mathrm{A}$

( R457H )

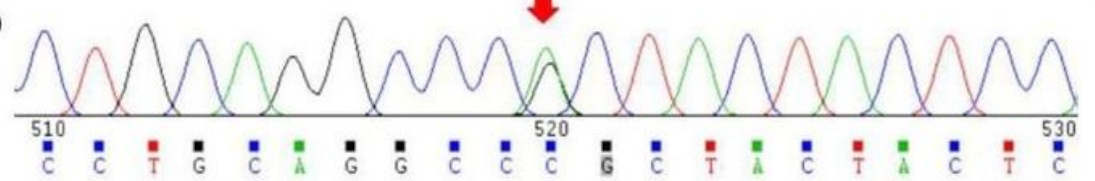

Maternal

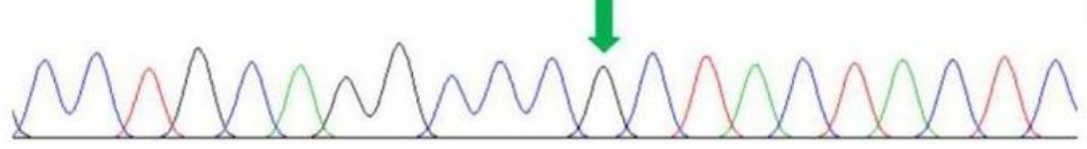

B

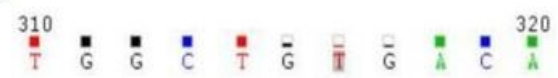

Patient $1660 \mathrm{C}>\mathrm{T}$

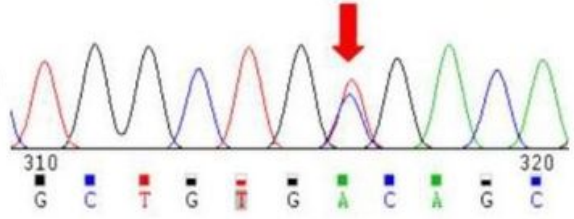

Paternal

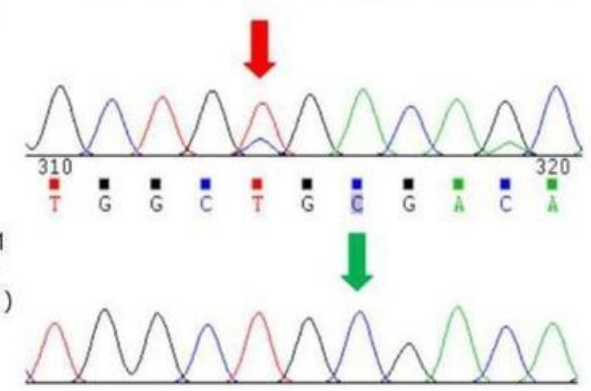

Figure 5

Gene sequence of patient 6 and parents with PORD. A) paternal mutation R457H, B) maternal mutation R554X. 


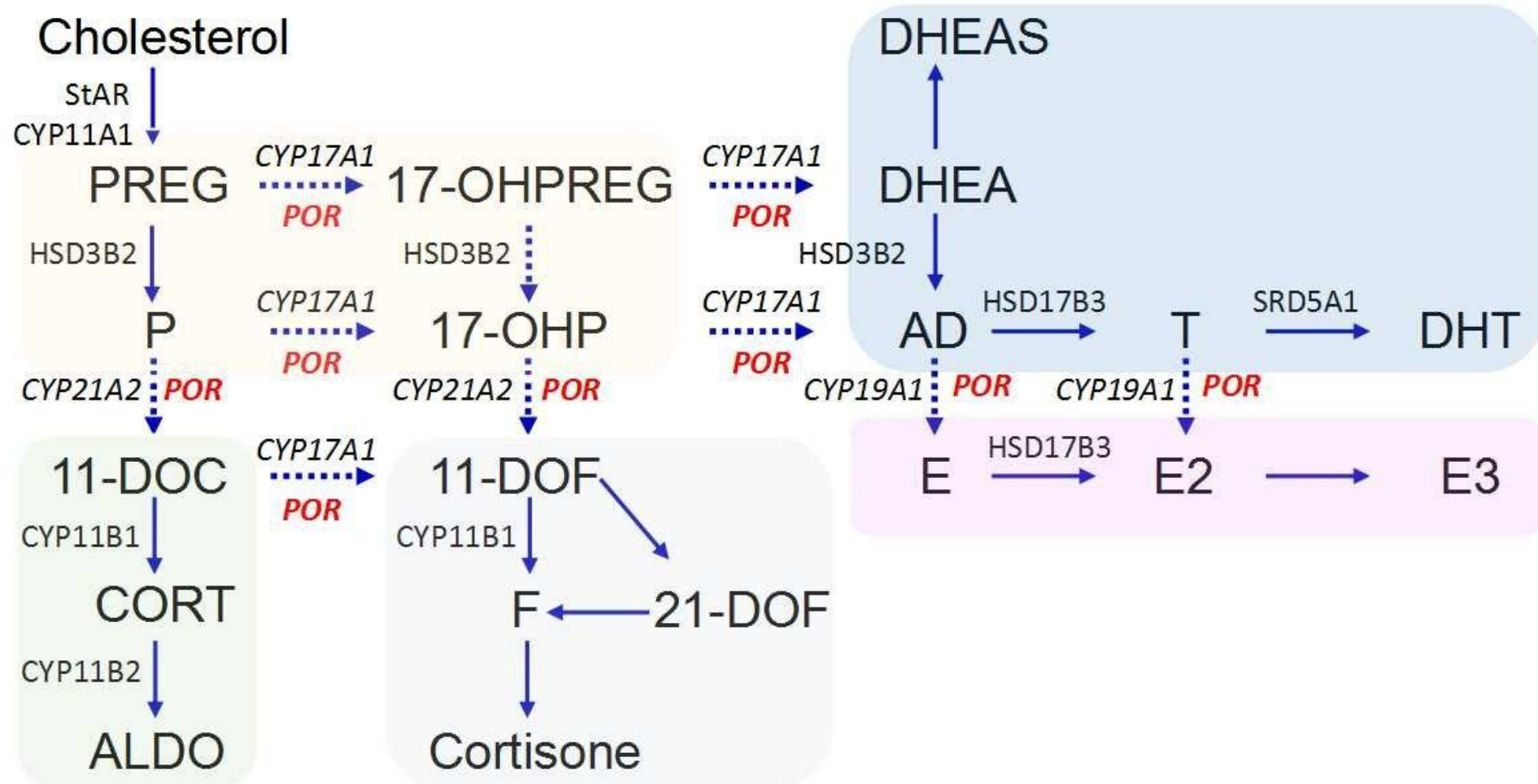

Figure 6

Steroidogenesis pathway of 19 evaluated hormones and relationship to P450 oxidoreductase. 